\title{
MEASURING AIR PRESSURE WITH A POLYMERIC GAS SENSOR\#
}

\author{
Juliana R. Cordeiro, Wanderson S. R. Teixeira, Renata Lippi, Rosamaria W. C. Li, Leonardo Ventura e Jonas Gruber* \\ Instituto de Química, Universidade de São Paulo, CP 26077, 05513-970 São Paulo - SP, Brasil
}

Recebido em 18/6/10; aceito em 12/10/10; publicado na web em 8/11/10

\begin{abstract}
In this communication we describe the application of a conductive polymer gas sensor as an air pressure sensor. The device consists of a thin doped poly(4'-hexyloxy-2,5-biphenylene ethylene) (PHBPE) film deposited on an interdigitated metallic electrode. The sensor is cheap, easy to fabricate, lasts for several months, and is suitable for measuring air pressures in the range between $100 \mathrm{and} 700 \mathrm{mmHg}$.
\end{abstract}

Keywords: gas sensor; pressure sensor; conductive polymer.

\section{INTRODUCTION}

Most commercially available pressure sensors are mechanical devices, which undergo structural changes caused by the deformation of a sensing element such as diaphragms, capsules, bellows and other components whose shape changes under pressure eventually converting these variations into electrical signals. ${ }^{1}$

Conductive polymer (CP) based gas sensors are chemoresistive devices easily assembled by the deposition of thin polymeric films onto interdigitated electrodes. ${ }^{2}$ These sensors change their electrical dc resistance (or ac impedance) upon exposures to a vapor. Both qualitative and quantitative measurements can be performed. ${ }^{2,3} \mathrm{Al}-$ though the response mechanism is still not clear at present, chemical sensing may occur either by swelling of the polymers by the vapor molecules, changing the interchain distances and, hence, the hopping process, or by charge-transfer interactions between the polymers and these vapor molecules. ${ }^{4}$

In this communication we report a novel application for a CPbased gas sensor. When exposed to dry air at different pressures in the range of 100 to $700 \mathrm{mmHg}$, its electrical conductance changes proportionally and reversibly. Hence, it can be used as a pressure sensor. As far as we know, this is the first CP-based pressure sensor ever described.

\section{EXPERIMENTAL}

\section{Synthesis}

Poly(4'-hexyloxy-2,5-biphenylene ethylene) (PHBPE) (Scheme 1) was prepared as previously reported ${ }^{2}$ by a palladium-catalyzed cross-coupling reaction ${ }^{5}$ of boronic acid $\mathbf{1}$ with aryl bromide $\mathbf{2}$, followed by bromination of the benzylic methyl groups of biphenyl 3 with $N$-bromosuccinimide (NBS) and controlled potential cathodic reduction ${ }^{6}$ of $\mathbf{4}$ leading to $\mathrm{PHBPE}$ in $87 \%$ yield.

\section{Preparation of the sensor and measurements}

A thin $(\sim 1 \mu \mathrm{m}$, determined using a Dektak3 surface profiler $)$ uniform layer of PHBPE doped with 10-canforsulfonic acid (CSA) was deposited onto an interdigitated electrode (Figure 1). The deposition was carried out by drop-casting $20 \mu \mathrm{L}$ of a solution containing $2.5 \mathrm{mg}$ of PHBPE, $0.7 \mathrm{mg}$ of CSA and $0.7 \mathrm{~mL}$ of chloroform. CSA

*e-mail: jogruber@iq.usp.br

"Dedicated to Prof. Hans Viertler on the occasion of his $70^{\text {th }}$ birth anniversary

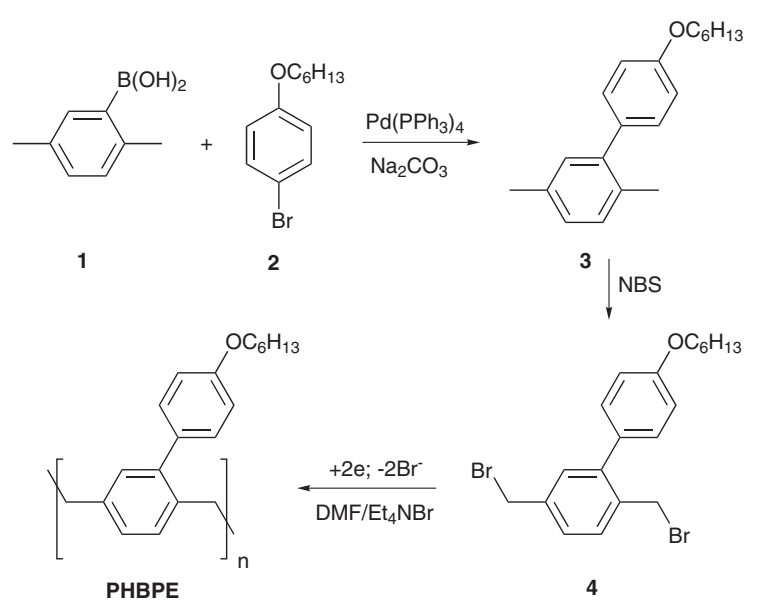

Scheme 1. Synthetic route to PHBPE

was chosen as dopant because it is a Lewis acid that presents good miscibility with the polymer. The electrode (Figure 1) consists of a flat $23 \times 9 \mathrm{~mm}$ fiberglass substrate with a pair of tin-coated copper interdigitated electrodes ( $200 \mu \mathrm{m}$ gaps, $300 \mu \mathrm{m}$ thickness) obtained from Micropress Ltda. by a silk-screen method usually used in printed circuit fabrication.

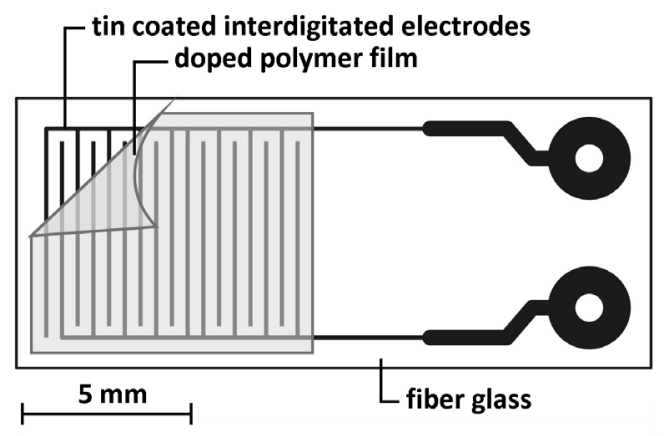

Figure 1. Top view of the sensor

The response of the sensor was evaluated by exposing it, in a closed $250 \mathrm{~mL}$ vessel (Figure 2), to dry atmospheric air, at $25^{\circ} \mathrm{C}$, at different pressures between 100 and $700 \mathrm{mmHg}$. In each experiment, the initial pressure was set at $100 \mathrm{mmHg}$, then increased stepwise (100 $\mathrm{mmHg} / \mathrm{step})$ to $700 \mathrm{mmHg}$ and decreased back to $100 \mathrm{mmHg}$ 
cyclically. The conductance of the sensor was read by a conductivity meter, ${ }^{7}$ constructed in our laboratory, converted to a digital signal that was transferred to a personal computer (PC) in which a software was used to plot graphs of conductance $v s$. time and conductance vs. pressure.



Figure 2. Setup of the equipment used for the measurements

\section{RESULTS AND DISCUSSION}

On exposure to dry air in a system (Figure 2) that allowed adjusting the internal pressure stepwise from 100 to $700 \mathrm{mmHg}$, and then back to $100 \mathrm{mmHg}$. Each test consisted of 17 such cycles. The sensor exhibited electrical conductance values that were proportional to the applied pressure and the observed responses were fast and reversible. The tests were repeated for several months. The graph shown in Figure 3 is a plot of conductance $(G)$ versus pressure $(P)$ and shows that there is a good correlation between them. The error bars represent the total error for each pressure based on data from many sets of 17 cycles each.



Figure 3. Plot of conductance versus pressure

In order to verify whether the sensor response is due to chemical interaction between the atmospheric air and the polymer or if it is due to a mechanical response, in which the increasing or decreasing pressure would result in conformational changes in the polymer chains that might cause the conductance to change accordingly, some similar tests were run using dry argon instead of air. No response was observed, which confirms that the nature of the response must be chemical. Probably, the sensor is sensible to one ore more specific compounds present in the air. The effect of humidity was checked exposing the sensor to air with relative humidity ranging from 30 to $\sim 100 \%$. No change in conductance was observed. This may be due to the hydrophobic nature of the $\mathrm{CP} .{ }^{8}$ Further investigations concerning the response mechanism of this sensor are beyond the scope of this short technical note and are being performed.

It is worth noting that the cost of a sensor is less than US\$ 1.00 and that the conductivity meter and A/D converter cost around US\$ 50.00. Finally, several sensors have been tested for over six months and are still responding perfectly well, as shown in Figure 4.

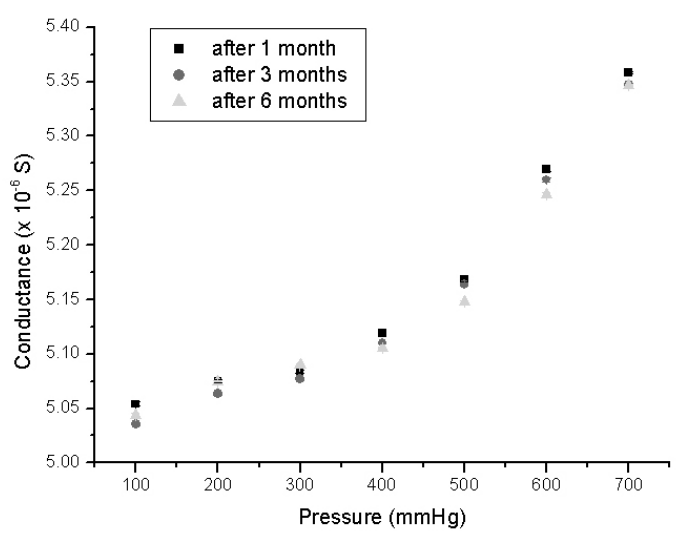

Figure 4. Plots of conductance versus pressure after 1, 3, and 6 months

\section{CONCLUSIONS}

Gas sensors made from 10-canforsulfonic acid doped poly(4'hexyloxy-2,5-biphenylene ethylene) films deposited onto interdigitated electrodes exhibit fast and reversible response towards dry air pressures in the range of 100 and $700 \mathrm{mmHg}$. Since there is no response when air is substituted by argon, the phenomenon should be a chemical interaction between a specific compound present in the air and the conductive polymer. The sensors are cheap, easy to fabricate and last for several months.

\section{ACKNOWLEDGEMENTS}

The authors would like to thank Conselho Nacional para o Desenvolvimento Científico e Tecnológico (CNPq) for its financial support.

\section{REFERENCES}

1. Fraden, J.; Handbook of Modern Sensors, $3^{\text {rd }}$ ed., Springer: New York, 2004.

2. Li, R. W. C.; Ventura, L.; Gruber, J.; Kawano, Y.; Carvalho, L. R. F.; Sens. Actuators, B 2008, 131, 646.

3. Benvenho, A. R. V.; Li, R. W. C.; Gruber, J.; Sens. Actuators, B 2009 , $136,173$.

4. Slater, J. M.; Watt, E. J.; Freeman, N. J.; May, I. P.; Weir, D. J.; Analyst 1992, 117, 1265.

5. Miyaura, N.; Suzuki, A.; Chem. Rev. 1995, 95, 2457.

6. Utley, J. H. P.; Gruber, J.; J. Mater. Chem. 2002, 12, 1613.

7. Rocha, R. T.; Gutz, I. G. R.; Lago, C. L.; J. Chem. Educ. 1997, 74, 572.

8. Li, R. W. C.; Carvalho, L. R. F.; Ventura, L.; Gruber, J.; Mater. Sci. Eng., C 2009, 29, 426. 